\title{
Multiple Peaked Cytokine Storm: Is Multiple Exposures to the COVID-19 Virus a Possible Cause?
}

\author{
Amarjeet $\operatorname{Kumar}^{1} \odot$, Abhyuday Kumar ${ }^{2} \odot$, Ajeet $\operatorname{Kumar}^{3} \odot$, Neeraj Kumar ${ }^{4} \odot$ Chandni Sinha $^{5} \odot$, Veena $\operatorname{Singh}^{6} \odot$
}

\begin{abstract}
Severe acute respiratory syndrome coronavirus 2 is the pathogen that causes coronavirus disease-2019 (COVID-19). Recent studies have shown that the "cytokine storm" (high concentration of proinflammatory cytokines) may contribute to the mortality of COVID-19. Repeated exposure to the virus can lead to a dose-dependent immune response that may be associated with more disease severity and higher mortality. Sudden deterioration/increased oxygen consumption after initial improvement may be due to multiple surges of cytokines storm within a short period, the possible cause may be due to multiple exposures within the incubation period. We hypothesize that multiple surges in cytokines storm in some patients may be due to multiple exposures of the same patient within the incubation period, sepsis, or other inflammatory lesions inside the body. In our cases, sepsis as a cause of cytokine storm was ruled out by doing the procalcitonin test, which was within the normal limit.

Keywords: Acute respiratory distress syndrome, COVID-19, Cytokine storm, Interleukin-6.

Indian Journal of Critical Care Medicine (2021): 10.5005/jp-journals-10071-23786
\end{abstract}

\section{INTRODUCTION}

Severe acute respiratory syndrome coronavirus 2 (SARS-Cov-2) is the pathogen that causes coronavirus disease-2019 (COVID-19). Recent studies have shown that the "cytokine storm" (high concentration of proinflammatory cytokines) may contribute to the mortality of COVID-19. ${ }^{1,2}$ About one-fifth of all infected patients progress to this stage of the disease and develop severe symptoms. SARSCoV-2 gets attached to angiotensin-converting enzyme 2 (ACE-2) receptors which are highly expressed on the pulmonary epithelial cells. ${ }^{3}$ After attachment to ACE- 2 receptors, the virus invades and enters the type 2 alveolar epithelial cells and starts replicating to produce more viral nucleocapsids. These pneumocytes then release many different cytokines and inflammatory markers such as interleukins (ILs), tumor necrosis factor-a (TNF-a) and interferons (IFNs), etc. This high level of cytokines is associated with a poor prognosis in COVID-19 patients. Postmortem examination has shown infiltration of proinflammatory cells, mainly involving macrophages, T-helper 17 cells in lung tissues of patients with COVID-19. Symptoms may develop 2 days to 2 weeks following exposure to the virus. ${ }^{4}$ The general trend of cytokine storm in COVID 19 is decrement after the first surge and it usually correlates with the clinical conditions of the patient.

\section{Case Descriptions}

Here we are going to report a situation in which the patient developed multiple surges in cytokine storm after an initial improvement in clinical condition and decrease in cytokines. Written and informed consent for publication was taken from the patient's relative.

\section{Case 1}

A 65-year-old COVID-19 positive male was admitted to the intensive care unit (ICU) due to respiratory distress. He was started on oxygen therapy, dexamethasone, low molecular weight heparin (LMWH), remdesivir, and other supportive measures. On admission,

\footnotetext{
${ }^{1,4}$ Department of Trauma and Emergency, All India Institute of Medical Sciences, Patna, Bihar, India

2,3,5 Department of Anaesthesiology, All India Institute of Medical Sciences, Patna, Bihar, India

${ }^{6}$ Department of Burns and Plastic Surgery, All India Institute of Medical Sciences, Patna, Bihar, India
}

Corresponding Author: Abhyuday Kumar, Department of Anaesthesiology, All India Institute of Medical Sciences, Patna, Bihar, India, Phone: +91 9013512403, e-mail: drabhyu@gmail.com

How to cite this article: Kumar A, Kumar A, Kumar A, Kumar N, Sinha C, Singh V. Multiple Peaked Cytokine Storm: Is Multiple Exposures to the COVID-19 Virus a Possible Cause? Indian J Crit Care Med 2021;25(4):463-464.

Source of support: Nil

Conflict of interest: None

inflammatory markers were raised. His condition improved by 3rd day of admission with decreased oxygen requirement with a decrease in inflammatory markers as well. However, on the 6th day his condition again deteriorated with increased oxygen requirement and raised inflammatory markers suggestive of cytokine storm (Table 1). Inflammatory markers again showed a nadir on the 15th day followed by a steep rise. The condition of the patient deteriorated in due course and the patient died on the 20th day.

\section{Case 2}

A 70-year-old COVID-19 positive female was admitted to the ICU with respiratory distress and high oxygen requirement. She was started on oxygen therapy, dexamethasone, LMWH, remdesivir, and other supportive measures as per hospital protocols. Her inflammatory markers were raised suggestively of cytokine storm. In due course, her condition improved with a decrease in the inflammatory markers. On the 12th day of illness, she was able to maintain oxygen saturation on room air. However, after the 18th 


\begin{tabular}{|c|c|c|c|c|c|}
\hline Date & $\begin{array}{l}\text { Oxygen } \\
\text { requirements (\%) }\end{array}$ & $\begin{array}{l}\text { IL-6 } \\
(\mathrm{pg} / \mathrm{mL})\end{array}$ & $\begin{array}{l}C R P \\
(\mathrm{mg} / \mathrm{L})\end{array}$ & $\begin{array}{l}L D H \\
(U / L)\end{array}$ & $\begin{array}{l}\text { Procalcitonin } \\
(\mathrm{ng} / \mathrm{mL})\end{array}$ \\
\hline \multicolumn{6}{|l|}{ Case 1} \\
\hline Day 1 & $60 \%$ (NRM) & 21.2 & 41.15 & 819.50 & 0.61 \\
\hline Day 3 & $40 \%(F M)$ & 3.5 & 62.70 & & 0.16 \\
\hline Day 6 & $80 \%$ (NRM) & 215 & & & $<0.10$ \\
\hline Day 10 & $80 \%$ (NIV) & 593.9 & 156 & & \\
\hline Day 13 & $80 \%$ (NIV) & & & & \\
\hline Day 15 & $100 \%$ (MV) & 30.9 & 24 & & \\
\hline Day 17 & $100 \%$ (MV) & 456 & 77 & 648 & 8.42 \\
\hline \multicolumn{6}{|l|}{ Case 2} \\
\hline Day 1 & $70 \%$ (NRM) & & 284 & 1303 & 1.02 \\
\hline Day 3 & $50 \%$ (NRM) & 129 & 84 & & \\
\hline Day 4 & $40 \%(F M)$ & & & & \\
\hline Day 8 & $33 \%$ (NP) & 10.6 & 20 & & \\
\hline Day 18 & $70 \%$ (NRM) & 95 & 184 & 714 & 1.08 \\
\hline Day 28 & $100 \%$ (MV) & & & & \\
\hline
\end{tabular}

Nonrebreathing mask (NRM), face mask (FM), nasal prong (NP), noninvasive ventilation (NIV), mechanical ventilation (MV), interleukin (IL), C-reactive protein (CRP), lactate dehydrogenase (LDH)

day her condition again deteriorated with high oxygen requirement and raised inflammatory markers. She succumbed to her illness on the 30th day of admission.

\section{Discussion}

Pathogens usually make us sick by two ways. One is by the direct effects and another indirect effect. Indirect effect is caused by activation of our hyperactive immune responses to the pathogen by the release of IFNs, ILs, TNF-a, chemokines, and several other mediators. This indirect mechanism plays a major role in severe COVID-19 infections. The "cytokine storm" caused by SARS-CoV-2 has been found to be a major cause of mortality in COVID-19 patients. The production of excessive cytokines and inflammatory markers leads to acute respiratory distress syndrome (ARDS) aggravation, thrombosis, and tissue damage resulting in multi-organ failure and death. . This "cytokine storm" leads to sequestration of neutrophils, CD4 helper T cells, and CD8 cytotoxic T cells in the lung tissue. In the process of fighting off the virus, these cells cause inflammation and lung injury. The virus-laden pneumocytes then undergo apoptosis with the release of new viral particles, which then infect the adjacent type 2 alveolar epithelial cells and the vicious cycle continues. This leads to loss of both type 1 and type 2 pneumocytes resulting in diffuse alveolar damage eventually causing ARDS.,

Huang et al. reported that severely infected patients show high levels of proinflammatory cytokines and chemokines. ${ }^{2}$ The cytokine storm is readily followed by the immune system "attacking" the body, which in turn can cause ARDS, multiple organ failure, and finally death. ${ }^{6}$

Repeated exposure to the virus can lead to a dose-dependent immune response that may be associated with more disease severity and higher mortality. ${ }^{7}$ Enhanced immune responses and exhaustion of immune cells can be seen in these patients due to persistent and large-scale viral infection. We hypothesize that multiple surges in cytokines storm in some patients may be due to multiple exposures of the same patient within the incubation period, sepsis, or other inflammatory lesions inside the body. In our cases, sepsis as a cause of cytokine storm was ruled out by doing the procalcitonin test, which was within the normal limit.

In our cases, the condition of the patient improved initially followed by a sudden deterioration in the clinical condition. This deterioration was not explained by any other cause except for an increase in the inflammatory markers. In the course of ICU stay patient showed multiple surges of inflammatory markers with waxing and waning of symptoms of the patient. Sudden deterioration/ increased oxygen consumption after initial improvement may be due to multiple surges of cytokines storm within a short period and the possible cause may be due to multiple exposures within the incubation period. This can be correlated with different stages of infiltrative lesions of the lung. There is a possibility that patients get reinfected in the hospital before the formation of an adequate antibody. It has been observed that healthcare workers have a high mortality rate and this might be because of multiple exposures to the virus during their duty hours. We can suspect multiple exposures whenever there are multiple surges in cytokines at different intervals. To validate our hypothesis, serial CT scan analysis or lung biopsy at different time intervals is required.

\section{OrCID}

Amarjeet Kumar $\odot$ https://orcid.org/0000-0002-4272-5750

Abhyuday Kumar (1) https://orcid.org/0000-0002-9247-6713

Ajeet Kumar (1) https://orcid.org/0000-0002-1464-6684

Neeraj Kumar $\odot$ https://orcid.org/0000-0002-9161-7000

Chandni Sinha 으 https://orcid.org/0000-0002-4107-2671

Veena Singh $\odot$ https://orcid.org/0000-0002-2120-6548

\section{References}

1. Ragab D, Salah Eldin H, Taeimah M, Khattab R, Salem R. The COVID-19 cytokine storm; what we know so far. Front Immunol 2020;16(11):1446. DOI: 10.3389/fimmu.2020.01446. PMID: 32612617; PMCID: PMC7308649.

2. Huang C, Wang Y, Li X, Ren L, Zhao J, Hu Y, et al. Clinical features of patients infected with 2019 novel coronavirus in Wuhan, China. Lancet 2020;395(10223):497-506. DOI: 10.1016/S0140-6736(20)30183-5.

3. Li W, Moore MJ, Vasilieva N, Sui J, Wong SK, Berne MA, et al. Angiotensinconverting enzyme 2 is a functional receptor for the SARS coronavirus. Nature 2003;426(6965):450-454. DOI: 10.1038/nature02145.

4. CDC. 2019 novel coronavirus, Wuhan, China: symptoms. CDC; January 26, 2020 [Accessed: January 27, 2020]. Available from: https://www. cdc.gov/coronavirus/2019-ncov/about/symptoms.html.

5. Cascella M, Rajnik M, Cuomo A, Dulebohn SC, Napoli RD, et al. Features, evaluation and treatment coronavirus (COVID-19). Stat pearls [internet]. Treasure Island (FL): Stat Pearls Publishing; Jan 2020.

6. Xu Z, Shi L, Wang Y, Zhang J, Huang L, Zhang C, et al. Pathological findings of COVID-19 associated with acute respiratory distress syndrome. Lancet Respir Med 2020;8(4):420-422. DOI: 10.1016/S22132600(20)30076-X.

7. Chen D, Hu C, Su F, Song O, Wang Z. Exposure to SARS-CoV-2 in a high transmission setting increases the risk of severe COVID-19 compared with exposure to a low transmission setting? J Travel Med 2020;27(5):taaa094. DOI: 10.1093/jtm/taaa094. 